\title{
Management of EMA-CO resistant/refractory gestational trophoblastic neoplasia
}

\author{
Abdulaziz Babaier ${ }^{1 *}$, Brent Jim ${ }^{2}$ and Prafull Ghatage ${ }^{2}$ \\ ${ }^{1}$ Department of Gynecologic Oncology, King Fahad Specialist Hospital, Dammam, Saudi Arabia \\ ${ }^{2}$ Department of Gynecologic Oncology, Tom Baker Cancer Centre, Calgary, Alberta, Canada
}

\begin{abstract}
The majority of gestational trophoblastic neoplasia (GTN) responds extremely well to first-line, multiagent chemotherapy employing etoposide, methotrexate, actinomycin D, cyclophosphamide, and vincristine (EMA-CO). However, up to 30\% of patients develop either resistance or recurrence. Although EMA-CO resistant GTN is a relatively rare disease, it can be challenging to manage. The cure rate to such a condition is highly dependent on the availability of an effective multiagent chemotherapy regimen with reasonable toxicity profile. Close monitoring of high-risk patients, early diagnosis and recognition is key for a successful outcome. Despite the primary role of chemotherapy in EMA-CO resistant disease, surgical interventions have been shown to improve survival and cure rate. A variety of multiagent chemotherapy regimens have shown efficacy in EMA-CO resistant disease. Unfortunately, to date, there is no strong evidence to suggest which regimen is the standard second-line therapy. Many patients require multiple regimens with or without surgery to achieve complete remission. Early and appropriate intervention is crucial to maximize the chance of cure. The aim of this review article is developing a comprehensive clinical guide for management of EMA-CO resistant GTN.
\end{abstract}

\section{Background}

Gestational trophoblastic disease (GTD) is a group of neoplastic disorders that arises from placental trophoblastic tissue after abnormal fertilization. It includes pre-malignant disease, which are complete and partial hydatidiform moles, and malignant disease, which includes choriocarcinoma, invasive mole, placental site trophoblastic tumor (PSTT), and epithelioid trophoblastic tumor (ETT). The malignant forms of GTD are collectively known as gestational trophoblastic neoplasia (GTN) [1].

Patients with GTN are classified as having low-risk or high-risk disease using the modified World Health Organization prognostic scoring system, that is adapted by the International Federation of Gynecology and Obstetrics (FIGO). High-risk is defined by FIGO stage IV or any FIGO stage with a score $\geq 7$, which indicates multi-agent chemotherapies as standard therapy $[2,3]$.

Since the development of effective chemotherapy, high-risk GTN has become one of the most curable human malignancies [4]. EMA/ CO (Etoposide, Methotrexate, Actinomycin D, Cyclophosphamide and Vincristine) is the most widely used primary combination therapy for high-risk GTN [5]. The remission rates of EMA/CO range from $71 \%$ to $91 \%[4,6,7]$. However, $30 \%$ to $40 \%$ of women will develop resistance or will relapse after initial remission and require salvage chemotherapy [5].

The relapse rate after initial compete response for high risk GTN is around $7-10 \%$ [8]. Unfortunately, around $20 \%$ of GTN relapses are incurable ${ }^{[9]}$. Importantly, about $83 \%$ of relapses occur within 18 months of complete response [10]. Failure to identify early relapses in patients who fail to follow up prevents early treatment when tumor load is still small and probably contribute to treatment failure [10].

The ultimate cure rate for resistant high-risk and relapsed GTN depends on the success of salvage chemotherapy with or without adjuvant surgical procedure. Despite the availability of various salvage regimens worldwide, it is unclear which regimens are the most effective and the least toxic. Management of high-risk EMA-CO resistant, relapsed GTN and the most widely used second line chemotherapies including their remission rates and toxicity profiles, are summarized in this review paper.

\section{Diagnosis of EMA-CO resistant GTN}

To date, there is no standard guideline to define the criteria for resistance to chemotherapy even though some physicians determine this condition by a plateau or rise in serum human chorionic gonadotropin (hCG) and/or development of new metastases. Feng et al. defined diagnosis of chemotherapy-resistant GTN as one of the following: A) two or more rising serum hCG levels despite receiving at least 2 courses of standard multi-agent chemotherapy, B) three or more consecutive hCG levels that have failed to decline more than $10 \%$ below the preceding hCG level, these patients are considered to have a plateau in their hCG, C) Increase size of tumor or development of new metastases during the multi-agent chemotherapy [11].

In 2012, Lybol et al. constructed nomogram for hCG regression in patients with high-risk GTN that were successfully treated with EMACO chemotherapy in an attempt to predict EMA-CO resistance. hCG levels were collected prior to each cycle of chemotherapy and plotted on

*Correspondence to: Abdulaziz Babaier, MD, SBOG, Department of Gynecologic Oncology, King Fahad Specialist Hospital, Dammam, Saudi Arabia, E-mail: Babaier82@gmail.com

Key words: gestational trophoblastic neoplasia, prognostic factors, refractory, resistance, second line chemotherapy, surgical interventions

Received: February 21, 2019; Accepted: March 01, 2019; Published: March 04 2019 
the $10^{\text {th }}, 50^{\text {th }}$, and $90^{\text {th }}$ percentiles to construct nomograms. They found that one-half of the patients with primary high-risk disease had normal hCG levels prior to $6^{\text {th }}$ cycle of chemotherapy. In patients with primary high-risk the $90^{\text {th }}$ percentile line fell below normal before the $8^{\text {th }}$ cycle of chemotherapy [12].

Subsequently, Rattanaburi et al. created hCG regression curves in high-risk GTN patients to determine if there was an optimal hCG level to predict EMA-CO resistance. They retrospectively plotted hCG regression curves for 81 patients treated with EMA-CO, they were classified as primary high-risk $(n=65)$ and single agent-resistant GTN $(n=16)$. hCG levels were drawn prior to each cycle of chemotherapy and plotted on the $10^{\text {th }}, 50^{\text {th }}$, and $90^{\text {th }}$ percentiles to construct their regression curves. They found that the $90^{\text {th }}$ percentile line fell below normal prior to $2^{\text {nd }}$ cycle of chemotherapy in single agent-resistant GTN patients and prior to the $9^{\text {th }}$ cycle in primary high-risk GTN patients. Using ROC analysis, they determined that an hCG level $\geq 118.6 \mathrm{mIU} / \mathrm{mL}$ measured prior to the $5^{\text {th }}$ cycle of chemotherapy provided the best diagnostic accuracy in predicting EMA-CO regimen resistance (sensitivity $85.7 \%$, specificity $100 \%$ ). The fifth cycle of EMA-CO is ideal because one-half of the patients with primary high-risk GTN had a normal hCG level prior to the start of the $4^{\text {th }}$ cycle [13].

\section{Prognostic factors for treatment failure}

Because the clinical significance of EMA-CO resistant disease, many investigators have endeavoured to recognise prognostic factors in cases of EMA-CO resistance. In 1998, Kim et al. described prognostic factors for treatment failure. They retrospectively reviewed 165 GTN patients who received the EMA-CO chemotherapy regimen [14]. Using univariate analysis, numerous factors were identified that predicted treatment failure. These factors include the following: A) tumor age "disease duration"; B) initial hCG titer; C) metastatic site (brain, liver and gastrointestinal metastases having an inferior prognosis); D) number of metastatic organs involved; E) unplanned operation; F) gravidity; G) and inadequate previous chemotherapy. They found that as the tumor ages, the death rates also increased from $5 \%$ (for less than 6 months) to $13 \%$ (for 7 to 12 months) and to $34.5 \%$ (for more than 12 months). Furthermore, as hCG values increased, the death rate also increased from $12.5 \%$ (for $<1000 \mathrm{mIU} / \mathrm{ml}$ ) to $34 \%$ (for $>100,000 \mathrm{mIU} /$ $\mathrm{ml})$. In terms of metastatic site, they found that if the metastatic site was confined to the lung and/or vagina, the death rate was $12 \%$, compared to $52 \%$ with metastases to the brain. Similarly, the number of metastatic organs had a significant effect on death rate. Not surprisingly, if the number of metastatic sites was zero, the death rate was only $4 \%$. This number increases to $18.5 \%$ with one site and to $64 \%$ with two or more sites. When an unplanned operation was performed, the death rate was $31 \%$, compared to $11 \%$ without one. Gravidity had a negative impact on death rate. The death rate was $12 \%$ in patients with gravidity $<4$, compared to $25.5 \%$ for patients with gravidity $>4$. In their multivariate analysis, the prognostic factors that are most important in determining a response to treatment in high-risk patients are: A) disease duration "tumor age" [greater than 12 months]; B) number of metastatic organs [2 or more sites]; C) metastatic sites apart from the vagina and lung; and D) inadequate previous chemotherapy. In patients with two or three of these factors, the death rates were $17.7 \%$ and $56.5 \%$, respectively. In a stepwise logistic regression of prognostic factors, tumor age and number of metastatic organ conferred the worst outcome and were considered independent high-risk factors for treatment failure [14].

Prognostic factors from other studies were mostly similar $[8,15]$. Lurain et al. reported that survival was influenced by hCG level, type of antecedent pregnancy, metastatic site, number metastatic sites, and WHO score, but only hCG level and metastatic site had a statistically significant effect. Patients with an hCG level $<100 \mathrm{mIU} / \mathrm{mL}$ at the start of salvage chemotherapy had a survival rate of $80 \%$ compared to $36 \%$ when the hCG level was $>100 \mathrm{mIU} / \mathrm{mL}$. Survival was $100 \%$ when there was no evidence of metastasis, $79 \%$ with metastases to the lung and vagina, and $36 \%$ with metastases to other sites [15]. Furthermore, Newlands et al. performed a multivariate analysis on recurrent and drug-resistant GTN and concluded the following were statistically significant adverse prognostic variables: the presence of liver metastases and brain metastases, long interval from antecedent pregnancy, and term delivery as antecedent pregnancy [8]. In addition, a few reports have documented that salvage therapy was more likely to fail in heavily pre-treated patients [16-18].

\section{Surgical management}

The development of effective chemotherapy has narrowed the importance of surgical approach in managing patients with GTN. However, adjuvant surgical procedures, mainly hysterectomy and pulmonary resection, for excision of chemotherapy resistant GTN still plays an important role in salvage therapy. In some patients with incomplete response to salvage chemotherapy regimen, surgical intervention could be useful in removing resistant tumor foci and improving outcomes in selected patients $[5,11,19,20]$. Salvage surgeries, including hysterectomy, pulmonary resection and uterine wedge resection could achieve complete remission in $85 \%$ of EMA-CO resistant patients [21]. The remission rate associated with thoracotomy and pulmonary resection, in carefully selected patients, is $73-90 \%$ $[26,28]$.

When surgery is considered in management of EMA-CO resistant, comprehensive metastatic survey should be performed, to document the extent of the disease. Complete assessment must include some or all of the following: detailed physical examination, complete blood count, liver function, renal function, hCG level, pelvic ultrasonography, CT chest abdomen and pelvis, CT/MRI brain, PET scan $[11,19]$.

Feng at al reported several clinical parameters associated with favorable outcomes in order to predict a therapeutic response to salvage surgery ${ }^{[11]}$. They compared patients who had successful treatment to those who did not. Several variables were found to be significantly different between the groups. The factors they found include: A) age; B) antecedent non-molar pregnancy; C) the presence of metastasis outside of the lungs; and D) preoperative serum hCG level. Remarkably, FIGO prognostic scores and preoperative cycles of chemotherapy were not statistically significant. A cut-off of 35 years of age gave the best sensitivity (70\%) and best specificity (57\%). For patients less than 35 years of age at surgery, $10 \%$ had treatment failure. When they compared patients greater than 35 years of age at surgery, $45.5 \%$ had treatment failure. A cut-off for preoperative serum hCG of $10 \mathrm{IU} / \mathrm{L}$ provided the best sensitivity $(60 \%)$ and best specificity $(82 \%)$. For those patients who had a preoperative hCG level less than $10 \mathrm{IU} / \mathrm{L}, 8.5 \%$ had treatment failure. In comparison, for those patients who had a preoperative hCG level greater than $10 \mathrm{IU} / \mathrm{L}, 43 \%$ had treatment failure. Multivariate analysis revealed that older patient age and higher preoperative serum hCG level were predictors of treatment failure. Each patient who experienced treatment failure had 2 or more of these adverse factors [11].

Proper assessment is crucial when deciding for surgery in chemotherapy resistant GTN. Feng and Xiang proposed four criteria to identify the ideal candidate for surgery in those patients [19]. The 
criteria of surgical management in patients with chemotherapyresistant GTN are: A) the performance status of the patients should be good enough to tolerate surgery. B) there should be no evidence of active tumor outside site of surgical resection. C) there should be no evidence of disseminated disease resistant to chemotherapy. D) preoperative hCG level should be as low as possible. To date, a known acceptable titer for preoperative hCG level is not available [19].

In 1980, Tomada et al. evaluated their results from planned resection of pulmonary nodules in GTN. Based on these results, they proposed guidelines for successful treatment: A) the patient must be a good candidate for surgical intervention; B) the primary malignancy must be controlled (i.e. the uterus has already been resected, or there is no radiological evidence of tumor in pelvic cavity); C) there is no evidence of metastatic disease; D) radiological evidence of pulmonary metastasis is limited to one lung; E) The urinary hCG level is below $1000 \mathrm{mIU} / \mathrm{mL}$. In their series, 14 of 15 patients (93\%) who satisfied all of these criteria were cured by pulmonary resection. In comparison, none of the patients who had 1 or more unfavorable factors were cured by pulmonary resection. The main indications for pulmonary surgical resection for choriocarcinoma are: A) urinary hCG values persisting at or below $1000 \mathrm{mIU} / \mathrm{mL}$ (but not under $16 \mathrm{mIU} / \mathrm{mL}$ ) in spite of longterm chemotherapy; and B) pulmonary metastases showing evidence of responding to treatment on chest x-ray [24]. In other words, ideal candidates for pulmonary resection are those patients who have residual pulmonary metastases that initially responded to chemotherapy, have no other evidence of disease based on diagnostic imaging, and have relatively low levels of hCG. Although prompt regression of hCG levels to normal after surgery is a favorable prognostic sign, post-operative chemotherapy should be considered [24]. In addition, Fleming et al. found that patients who survived after thoracotomy for GTN were likely to have: A) perioperative hCG less than $1500 \mathrm{mIU} / \mathrm{mL}$; B) stage III disease (no liver or brain metastases); and C) solitary pulmonary nodule [22]. Several investigators have reported that the achievement of non-detectable hCG within 1-2 weeks after resection of a solitary pulmonary nodule is highly predictive of favorable outcome $[2,19]$. Cao et al. reported that the patients with chemotherapy-resistant GTN who received more than four regimens or 13 cycles of pre-operative chemotherapy had a poor prognosis and were less likely to benefit from pulmonary lobectomy [26].

While GTN is mainly a disease of reproductive age, fertility sparing local uterine resection may be an option for patient who desires to preserve fertility as long as she understands the risk of such approach and the possible consequences. It is important to precisely determine the size and the location of the disease, ultrasonography and/or MRI are helpful in that purpose [19].

Other surgical interventions could be considered in selected patients. After lung, the vagina is the second most common metastatic site in GTN [27]. The principal treatment for vaginal metastases is chemotherapy. Surgical excision of vaginal metastases should be avoided, due to high vascularity, unless the lesion represents the only site of drug-resistant disease [19]. Brain metastases occur in $8-15 \%$ of the patients with metastatic GTN. Currently, the practice for treating patients with brain metastases consists of an intensive multi-agent chemotherapy, intrathecal methotrexate, whole brain radiation therapy, and neurosurgical intervention. However, craniotomy for resection of chemotherapy-resistant brain lesion is rarely performed. In rare circumstances, cerebral metastases that are resistant to chemotherapy could be amenable to local resection, particularly if they are localized at the periphery. In general, craniotomy is reserved for women who require acute decompression of CNS hemorrhagic lesions to allow stabilization and initiation of therapy $[19,28]$. Liver metastases are an ominous feature and the reported survival rates are generally poor. Hepatic resection may be necessary to control acute hepatic bleeding or to remove localized areas of resistant tumor. Resection of isolated liver metastases is rarely feasible for treatment of chemotherapy-resistant disease, because most patients will have other sites of active disease or disseminated involvement of the liver [19].

\section{Second lines chemotherapy for GTN}

As we mentioned before, up to $30 \%$ of high risk GTN will develop resistant to primary chemotherapy regimens or have relapse after initial therapy. Salvage rate depends on the use of effective chemotherapy regimens with high cure rate. The salvage rate for resistant GTN is around $88 \%$ [8]. Some patients might require multiple chemotherapy regimens to achieve remission after developing EMA-CO resistant [29]. Experts have strongly recommended that GTNs are best treated by chemotherapy that is administered at frequent intervals and the interval between courses should rarely exceed 14-21 days depending on the chemotherapy regimens $[27,29,30]$. Treatment delay or dose reduction due to chemotherapy-induced neutropenia may contribute to tumor resistance and treatment failure [2]. The commonly used secondline regimens in GTN will be discussed, including the detailed regimen, remission rate and toxicity profile.

\section{EMA-EP}

EMA-EP (Etoposide, Methotrexate, Actinomycin D-Etoposide, Cisplatin) is the most common salvage chemotherapy regimen in EMACO resistant GTN, and the most commonly regimen used in Charing Cross Hospital [8]. It seems to be the most appropriate chemotherapy for patients who have initially responded to EMA-CO but have plateauing low hCG levels or who have developed re-elevation of hCG levels after having had a complete response to EMA-CO [31,32]. The remission rate associated with EMA-EP is $70-80 \%[4,8,33]$.

The regimen is summarized in Tables 1 and 2 [34,35]. At least two different schedule are used, one from Charing Cross Hospital, UK [31] and the other one from Women's Hospital in Zhejiang University, China [32]. This regimen is repeated every 2 weeks. Response to chemotherapy is assessed weekly by measuring serum hCG levels, and monthly by a physical examination including a pelvic examination and a chest radiograph or a computed tomographic scan [32]. After undetectable hCG values are achieved, two to four additional courses of chemotherapy are administered to reduce the risk of relapse and eradicate all tumor cells $[2,32]$.

Table 1. EMA-EP schedule from women's hospital at Zhejiang university, China

\begin{tabular}{|c|c|}
\hline Regimen & Dose \\
\hline $\begin{array}{l}\text { Day } 1 \\
\text { Etoposide } \\
\text { Actinomycin D } \\
\text { Methotrexate }\end{array}$ & $\begin{array}{l}100 \mathrm{mg} / \mathrm{m}^{2} \mathrm{IV} \text { over } 30 \mathrm{~min} \\
0.5 \mathrm{mg} \mathrm{IV} \text { push } \\
100 \mathrm{mg} / \mathrm{m}^{2} \mathrm{IV} \text { push } \\
200 \mathrm{mg} / \mathrm{m}^{2} \mathrm{IV} \text { infusion in } 100 \mathrm{ml} \mathrm{NS} \text { over } 12 \text { hours }\end{array}$ \\
\hline $\begin{array}{l}\text { Day } 2 \\
\text { Etoposide } \\
\text { Actinomycin D } \\
\text { Folinic acid }\end{array}$ & $\begin{array}{l}100 \mathrm{mg} / \mathrm{m}^{2} \mathrm{IV} \text { over } 30 \mathrm{~min} \\
0.5 \mathrm{mg} \text { IV push } \\
15 \mathrm{mg} \text { IM every } 12 \text { hours for four doses, beginning } 24 \text { hours } \\
\text { after start of methotrexate }\end{array}$ \\
\hline $\begin{array}{l}\text { Day } 8 \\
\text { Etoposide } \\
\text { Cisplatin }\end{array}$ & $\begin{array}{l}100 \mathrm{mg} / \mathrm{m}^{2} \mathrm{IV} \\
80 \mathrm{mg} / \mathrm{m}^{2}\end{array}$ \\
\hline
\end{tabular}

IV: Intravenous; IM: Intramuscular; NS: Normal saline 
Table 2. EP-EMA schedule from Charing Cross hospital, UK

\begin{tabular}{|c|c|}
\hline Regimen & Dose \\
\hline $\begin{array}{l}\text { Day } 1 \\
\text { Etoposide } \\
\text { Cisplatin } \\
\text { Cisplatin } \\
\text { Cisplatin }\end{array}$ & $\begin{array}{l}150 \mathrm{mg} / \mathrm{m}^{2} \text { IV in } 250 \mathrm{ml} \mathrm{NS} \text { over } 30 \mathrm{~min} \\
25 \mathrm{mg} / \mathrm{m}^{2} \text { IV in } 1 \mathrm{~L} \mathrm{NS}+20 \mathrm{mmol} \mathrm{KCL} \text { over } 4 \text { hours } \\
25 \mathrm{mg} / \mathrm{m}^{2} \text { IV in } 1 \mathrm{~L} \mathrm{NS}+20 \mathrm{mmol} \mathrm{KCL} \text { over } 4 \text { hours } \\
25 \mathrm{mg} / \mathrm{m}^{2} \text { IV in } 1 \mathrm{~L} \mathrm{NS}+20 \mathrm{mmol} \mathrm{KCL} \text { over } 4 \text { hours } \\
\text { (Total dose of Cisplatin } 75 \mathrm{mg} / \mathrm{m}^{2} \text { over } 12 \text { hours) }\end{array}$ \\
\hline $\begin{array}{l}\text { Day } 8 \\
\text { Etoposide } \\
\text { Methotrexate } \\
\text { Actinomycin D }\end{array}$ & $\begin{array}{l}100 \mathrm{mg} / \mathrm{m}^{2} \mathrm{IV} \text { in } 250 \mathrm{ml} \text { NS over } 30 \mathrm{~min} \\
300 \mathrm{mg} / \mathrm{m}^{2} \mathrm{IV} \text { in } 1 \mathrm{~L} \mathrm{NS} \text { over } 12 \text { hours } \\
0.5 \mathrm{mg} \mathrm{IV} \text { bolus }\end{array}$ \\
\hline $\begin{array}{l}\text { Day } 9 \\
\text { Folinic acid }\end{array}$ & $\begin{array}{l}15 \mathrm{mg} \text { orally or intramuscularly twice daily for } 4 \text { doses } \\
24 \text { hours after start of methotrexate }\end{array}$ \\
\hline
\end{tabular}

IV: Intravenous; NS: Normal saline

Toxicity profile of EMA-EP regimen is relatively bearable. It requires careful monitoring for renal function since cisplatin is nephrotoxic and methotrexate is renally excreted [29]. Main toxicities are hematological and renal, in addition to other mild toxicities associated with cytotoxic chemotherapy [31,32]. Bone marrow suppression is the most common adverse effect, without the support of G-CSF (Granulocyte Colony Stimulating Factor). Therefore, it requires G-CSF support for three or four days between each cycle of chemotherapy in order to maintain the momentum of treatment and avoid delays $[5,29]$. Grade 3 and 4 neutropenia occurs in up to $68 \%$, and grade 3 and 4 thrombocytopenia is around $40 \%$. While grade 1 and 2 nephrotoxicity occurs in $40 \%$, mild hepatotoxicity affects $2.6 \%$ only $[31,32]$.

\section{TP/TE}

The TP/TE doublet regimen (Paclitaxel+Cisplatin/Paclitaxel Etoposide) is fairly well tolerated despite extensive previous chemotherapy, and is safe and effective in relapsed, high-risk heavily treated patients with GTN [17,34]. The overall survival associated with this regimen is $70-75 \%$, but less in patients who received prior platinum-containing therapy [17]. It is a good alternative option to EMA/EP with less toxic profile.

The regimen at Charing Cross Hospital is summarized in Table 3 [17]. Osborne et al. in Toronto used slightly modified protocol [34]. The regimen used in Toronto as following:

- Day 1 - Paclitaxel $135 \mathrm{mg} / \mathrm{m}^{2}$ over 3 hours+Etoposide $150 \mathrm{mg} / \mathrm{m}^{2}$ over 30 minutes.

- Day 15 - Paclitaxel $135 \mathrm{mg} / \mathrm{m}^{2}$ over 3 hours+Cisplatin $75 \mathrm{mg} / \mathrm{m}^{2}$ over 1 hour.

TP is alternating every 2 weeks with TE, or vice versa, to form one cycle of therapy. Prophylactic subcutaneous injections of G-CSF for 3-4 days are used. Patients receiving chemotherapy are assessed by hCG levels twice weekly. Treatment is discontinued when the hCG is normal for 8 weeks.

The most common toxicity is grade 3 and 4 neutropenia which occurs in $42 \%$, while grade 3 and 4 thrombocytopenia develops in $13 \%$ only. In addition, mild nausea and peripheral neuropathy is recorded in $13 \%$ and $21 \%$, respectively [17].

\section{BEP}

BEP (Bleomycin, Etoposide, Cisplatin) protocol have been also used in refractory GTN $[15,35]$. The complete response in high-risk GTN, as primary and secondary therapy, is around $89 \%$, with or without surgery and/or radiotherapy [35]. However, this regimen achieves complete response in about $74 \%$ of persistent/relapsed high-risk gestational trophoblastic neoplasia [15]. Moreover, Zhao et al. reported remission rate of 83.3\% in FA (5-FU and Actinomycin D) resistant patients [36].

The most commonly used BEP protocol is summarized in Table 4 [15]. Pulmonary function tests are obtained prior to each dose of bleomycin to monitor for pulmonary toxicity and a maximum of 270 units of bleomycin is given.

The treatment is repeated every 21 days. In order to reduce the incidence of severe neutropenia and avoid treatment delays, G-CSF 300 mcg is administered on days 6-14 of each treatment cycle. Three cycles of chemotherapy after negative serum B-hCG are given [15,35].

The most common side effects with BEP protocol are alopecia (98.5\%), nausea and vomiting (72\%), neutropenia (68\%) and peripheral neuropathy (44\%). Whereas all these toxicities are grade 1 and 2 , grade 3 and 4 neutropenia occur in $9 \%$. Other grade 1 side effects include thrombocytopenia, hepatotoxicity, cardiac toxicity and pulmonary toxicity in $16 \%, 11 \%, 4 \%$ and $2.5 \%$, respectively [35].

\section{5-FU/Actinomycin-D (FA)}

In China, the FA protocol is often used as the first-line chemotherapy regimen for both low and high risk patients with GTN, while EMA-CO and BEP are used as second-line therapy [36]. Remission rate with FA as primary therapy in high risk GTN reach around $85 \%$ [36], with or without surgery, and up to $80 \%$ as salvage chemotherapy [37].

The FA regimen is given over 5 days, Day 1-5, containing daily dose of 5-Fluorouracil $1500 \mathrm{mg}$ IV infusion over 8 hours and Actinomycin-D $0.5 \mathrm{mg}$ IV bolus [37]. In case of brain metastases, intrathecal methotrexate is added to the protocol [36]. A satisfactory response was defined as at least 1 log decrease in hCG level after each chemotherapy course. Response to the FA regimen was assessed by measuring serum human chorionic gonadotropin (hCG) levels twice weekly. Chemotherapy was repeated in 2 -week or 3 -week intervals until the serum hCG level decreased to normal. Once the hCG level is undetectable, patients should receive additional seven cycles [37].

Table 3. TP/TE protocol

\begin{tabular}{|c|c|}
\hline Regimen & Dose \\
\hline $\begin{array}{l}\text { Day } 1 \\
\text { Dexamethasone } \\
\text { Cimetidine } \\
\text { Chlorphenamine } \\
\text { Paclitaxel } \\
\text { Mannitol } \\
\text { Cisplatin } \\
\text { Post-hydration }\end{array}$ & $\begin{array}{l}20 \mathrm{mg} \text { oral } 12 \text { and } 6 \text { h prior Paclitaxel } \\
30 \mathrm{mg} \text { in } 100 \mathrm{ml} \mathrm{NS} \text { over } 30 \mathrm{~min} \text { IV } \\
10 \mathrm{mg} \text { bolus IV } \\
135 \mathrm{mg} / \mathrm{m}^{2} \text { in } 250 \mathrm{ml} \mathrm{NS} \text { over } 3 \mathrm{~h} \mathrm{IV} \\
10 \% \mathrm{in} 500 \mathrm{ml} \text { over } 1 \mathrm{~h} \\
60 \mathrm{mg} / \mathrm{m}^{2} \text { in } 1 \mathrm{~L} \mathrm{NS} \text { over } 3 \mathrm{~h} \mathrm{IV} \\
1 \mathrm{~L} \mathrm{NS}+\mathrm{KCL} 20 \mathrm{mmol}+1 \mathrm{MgSO}_{4} \text { over } 2 \mathrm{~h} \mathrm{IV}\end{array}$ \\
\hline $\begin{array}{l}\text { Day } 15 \\
\text { Dexamethasone } \\
\text { Cimetidine } \\
\text { Chlorphenamine } \\
\text { Paclitaxel } \\
\text { Etoposide }\end{array}$ & $\begin{array}{l}20 \mathrm{mg} \text { oral } 12 \text { and } 6 \mathrm{~h} \text { prior Paclitaxel } \\
30 \mathrm{mg} \text { in } 100 \mathrm{ml} \mathrm{NS} \text { over } 30 \mathrm{~min} \text { IV } \\
10 \mathrm{mg} \text { bolus IV } \\
135 \mathrm{mg} / \mathrm{m}^{2} \text { in } 250 \mathrm{ml} \mathrm{NS} \text { over } 3 \mathrm{~h} \mathrm{IV} \\
150 \mathrm{mg} / \mathrm{m}^{2} \text { in } 1 \mathrm{~L} \mathrm{NS} \text { over } 1 \mathrm{~h} \mathrm{IV}\end{array}$ \\
\hline
\end{tabular}

H: Hour; L: Liter; NS: Normal saline; IV: Intravenous; KCL: Potassium chloride; $\mathrm{MgSO}_{4}$ : Magnesium sulfate

Table 4. BEP protocol

\begin{tabular}{|c|c|c|}
\hline Regimen & Dose & Duration/Schedule \\
\hline Bleomycin & $30 \mathrm{Unit}$ Intravenously & Days $1,8,15$ \\
\hline Etoposide & $100 \mathrm{mg} / \mathrm{m}^{2}$ Intravenously & Days $1-4$ \\
\hline Cisplatin & $20 \mathrm{mg} / \mathrm{m}^{2}$ Intravenously & Days $1-4$. \\
\hline
\end{tabular}


The toxicity profile mainly involves the gastrointestinal tract. Almost all patients develop grade 1 or 2 nausea and emesis which can be treated with standard antiemetics, but $48 \%$ will have grade 3 vomiting. Furthermore, grade 3 and 4 diarrhea and oral mucositis might occur in $54 \%$ and $30 \%$, respectively. Whereas grade 3 and 4 leukopenia are as common as $42 \%$, thrombocytopenia occurs in $12 \%$ as grade 1 and 2 only. In addition, grade 3 alopecia develop is almost all patients, but they recover within 6 months after completion of chemotherapy. Rarely, elevated liver enzyme might affect $9 \%$ of the patients [36,37].

\section{FAEV}

The FAEV (Floxuridine, Actinomycin D, Etoposide, Vincristine) regimen has been mainly used in China, as primary therapy in very high-risk GTN as well as salvage chemotherapy $[18,38]$. As the first line multi-agent chemotherapy in primary setting, remission rate is about $80 \%$ [38]. On the other hand, the remission rate as salvage therapy is $60 \%$, with or without surgery [18].

The FAEV regimen is outlined in Table 5 [38]. The chemotherapy is cycled in 21-day intervals. Three additional courses of chemotherapy after normalization of the B-hCG level are given. Of note, prophylactic G-CSF is not given routinely in this regimen. In patients with brain metastasis, intrathecal methotrexate is added to the protocol. The most common adverse events encountered were nausea (59.3\%), anemia (53.8\%), fatigue (50\%), neutropenia (48\%), and anorexia (45\%). The majority of these episodes are categorized as grade 1 or 2 . However, grade 3 and 4 neutropenia occurs in 26\% and thrombocytopenia in 3\% [18]. For this reason, introducing prophylactic G-CSF in the regimen could be considered.

\section{Other second line therapy}

There are multiple other less used chemotherapy regimens which could be utilized in certain patients. We will try to briefly address these protocols including their remission rates.

APE: APE (Actinomycin, Cisplatin, Etoposide) protocol is used as first line or salvage therapy [39]. The remission rate associated with this regimen is as high as $94 \%$, in both primary or recurrence setting, even after multiple prior chemotherapy. However, this rate drops to $85 \%$ once FIGO scoring system is over 12 [39]. As this regimen does not include methotrexate, it is not offered to patients with brain metastasis. Different scheduling for APE regimen is summarized in Table 6 [39]. Chemotherapy is administered until human serum chorionic gonadotropin (hCG) levels decrease to within the normal range plus a further six weeks. This regimen resulted in acceptable rates of acute

Table 5. The FAEV regimen

\begin{tabular}{|l|l|l|l|}
\hline Regimen & Dose & Duration & Schedule \\
\hline Floxuridine & $800 \mathrm{mg} / \mathrm{m}^{2}$ & D1-5 & Administered by infusion more than 8 hour \\
\hline Actinomycin D & $200 \mu \mathrm{g} / \mathrm{m}^{2}$ & D1-5 & Administered by infusion more than $30 \mathrm{~min}$ \\
\hline Etoposide & $100 \mathrm{mg} / \mathrm{m}^{2}$ & D1-5 & Administered by infusion more than $30 \mathrm{~min}$ \\
\hline Vincristine & $2 \mathrm{mg}$ & D1 & $\begin{array}{l}\text { Administered by bolus intravenously } 3 \text { hours } \\
\text { before treatment with Actinomycin }\end{array}$ \\
\hline
\end{tabular}

D: Day; min: Minute

Table 6. APE regimen

\begin{tabular}{|c|c|c|c|c|}
\hline Regimen & $\begin{array}{c}\text { Actinomycin } \\
\left.\mathbf{( 0 . 3} \mathbf{~ m g} / \mathbf{m}^{2} / \mathbf{d}\right)\end{array}$ & $\begin{array}{c}\text { Etoposide } \\
\left.\mathbf{( 1 0 0 ~} \mathbf{~ m g} / \mathbf{m}^{2} / \mathbf{d}\right)\end{array}$ & Cisplatin & Cycle \\
\hline Regimen 1 & D1-3, D14-D15 & D1-3, D14-D15 & D1, $100 \mathrm{mg} / \mathrm{m}^{2}$ & Every 28 days \\
\hline Regimen 2 & D1-D3 & D1-D3 & D1, $100 \mathrm{mg} / \mathrm{m}^{2}$ & Every 21 days \\
\hline Regimen 3 & D1-D3 & D1-D3 & $\mathrm{D} 1,75 \mathrm{mg} / \mathrm{m}^{2}$ & Every 21 days \\
\hline
\end{tabular}

D: Day toxicity and limited long-term toxicities, there is no unusual toxicity to other cisplatin/etoposide containing protocol.

VIP and ICE: The VIP protocol as following: Etoposide $75 \mathrm{mg} / \mathrm{m}^{2}$ intravenously (IV); Ifosfamide $1.2 \mathrm{gm} / \mathrm{m}^{2}$ (IV); and Cisplatin $20 \mathrm{mg} /$ $\mathrm{m}^{2}$ (IV) every day for 4 days. Mesna is given as a $120 \mathrm{mg} / \mathrm{m}^{2}$ (IV) bolus preceding the first dose of ifosfamide, followed by a $1.2 \mathrm{gm} / \mathrm{m}^{2} 12$-hour (IV) infusion daily after each ifosfamide dose. If significant cisplatininduced renal or neurologic toxicity occurs, Cisplatin is replaced by Carboplatin in the ICE protocol. The ICE regimen is: Ifosfamide 1.2 $\mathrm{gm} / \mathrm{m}^{2}$ on days 1-3, with mesna as above doses; Carboplatin $300 \mathrm{mg} /$ $\mathrm{m}^{2}$ (IV) on day 1; and Etoposide $75 \mathrm{mg} / \mathrm{m}^{2}$ on days $1-3$ [15]. These regimens are repeated every 21 days. In order to reduce the occurrence of severe neutropenia and prevent treatment delays, granulocyte colony stimulating factor (G-CSF) $300 \mathrm{mcg}$ is given subcutaneously on days $6-14$ of each treatment cycle. The complete response rate is documented to be around $67 \%$ in patients treated with these regimen [15].

PVB: The PVB protocol is consisted of Vinblastine $0.3 \mathrm{mg} / \mathrm{kg}$ intravenously (IV) on day 1 , Bleomycin $15 \mathrm{mg} /$ day as a continuous infusion on days 1, 2, 3, and Cisplatin $100 \mathrm{mg} / \mathrm{m} 2$ (IV) on day 2 with extra-hydration and mannitol diuresis to minimize renal toxicity [40]. The treatment is introduced at 21 -day intervals. The cure rate with PVB protocol in high risk resistant GTN is $62 \%$, with or without surgery or brain radiotherapy. The regimen is well tolerated with no major toxicities, no grade 3 or 4 toxicity.

Fluorouracil (5-FU), Methotrexate (MTX) and Etoposide (VP16): 5 -FU based chemotherapy is used commonly in China. 5-FU, MTX and VP-16 schedule for 5 days with an interval of 14 days between courses. The doses for the regimen are 5-FU $26 \mathrm{mg} / \mathrm{kg}$ Intravenously (IV), MTX $0.3 \mathrm{mg} / \mathrm{kg}$ Intramuscularly (IM), Etoposide $100 \mathrm{mg}$ IV [41]. Chemotherapy is repeated until three consecutive weekly hCG level are normal, and following that, an additional 1- 2 cycles is given. The remission rate in previously treated patients is $78 \%$ [41]. Common side effects include bone marrow suppression, nausea and vomiting, diarrhea, hepatotoxicity and mucositis. These side effects are mainly grade 1 and 2, but neutropenia and nausea and vomiting could become grade 3 and 4 in 25 and $40 \%$, respectively [41].

Paclitaxel and carboplatin: Paclitaxel and Carboplatin protocol has been also used in resistant GTN [42]. The regimen is paclitaxel 175 $\mathrm{mg} / \mathrm{m}^{2}$ and carboplatin (area under the curve, 6) and is administered every 3 weeks' interval. After undetectable B -hCG values are achieved, 2 additional courses of chemotherapy are administered to reduce the risk of relapse. The remission rate has reached $62 \%$ [42].

High-dose chemotherapy (HDC) and peripheral blood stem cell support: High-dose chemotherapy and peripheral blood stem cell support has been used to manage refractory GTN cases $[43,44]$. While the results of such approach have shown mixed outcome, it could be an options for selective high risk refractory GTN who fail multiple salvage therapies [43]. Based on few case reports and series, complete remission was achieved in 50\%,11 out of 22 patients [45]. However, the survival time after complete response in 4 cases was $<4$ months. The most commonly used regimen is HDC is ICE. Other used regimens include EC (Etoposide/Cyclophosphamide), CEM (Cyclophosphamide, Etoposide, Melphalan), EP (Etoposide, Cisplatin) and Carb-EC (Carboplatin, Etoposide, Cyclophosphamide). The majority of patients received only one cycle, but up to 4 cycles of HDC with steam cell support were given [45]. 


\section{Radiotherapy}

Radiotherapy play an important part in improving the outcome of challenging refractory/resistant GTN disease, mainly in cerebral metastasis. When brain metastasis is diagnosed, addition of whole brain irradiation to systemic chemotherapy has proven to increase the chance of cure [46-48]. Whole-brain irradiation, 2400-3000 cGy in $200 \mathrm{cGy}$ fractions, has a dual advantage of being tumoricidal and hemostatic, should be administered simultaneously with the initiation of chemotherapy. In addition, brain irradiation provides excellent local control of brain disease. Radiotherapy must be avoided in clinically unstable patient due to cerebral lesion as it may worsen the clinical condition.

\section{Post treatment follow up}

Complete response is defined as an achievement of three consecutive weekly normal hCG levels and the disappearance of metastasis $[5,33]$. Follow up and surveillance after complete response to chemotherapy in resistant GTN disease is crucial. Depending on the regimen used and initial status of the disease, at least two additional courses of chemotherapy are given after normal hCG value. Lu et al. recommended follow up of all patients with weekly hCG levels in the first three months after finishing chemotherapy, then monthly until 24 months [33]. However, Lurain et al. at Brewer Trophoblastic Disease Center, follow up their patients with monthly hCG levels for 12 months and every 3 months during the second year [5]. Mutch et al. reported that relapses developed within 3 and 18 months in 50 and $85 \%$ of patients, respectively [49]. Patients are advised not to conceive for 1 year after completing therapy and to have an hCG level obtained 6 weeks after any future pregnancy. Oral contraceptive pills are usually prescribed during chemotherapy, unless contraindicated, to prevent pregnancy, to decrease the risk of ovarian failure, and to suppress endogenous luteinizing hormone and follicle stimulating hormone which may interfere with the measurement of hCG at low level [5].

\section{Expert commentary}

Management of EMA-CO resistance GTN is challenging and can be way very complicated. These patients mostly are young and in their reproductive age, but they require aggressive management surgically and medically. Awareness about prognostic factors and patient characteristics associated with resistant disease is vital in early recognition of such condition. Careful and appropriate monitoring of serum hCG levels is fundamental to provide early and timely interventions which should offer the best chance for cure. Knowing the fact that mortality rate is around 20 percent, this disease requires proper and assertive management.

Availability of many proven efficacy multiagent chemotherapy regimens should be an assist to the treating physician in managing such a disease. Regimen choice depends on previous chemotherapy received, patient tolerance to specific agents and previous chemotherapy side effects. Taking into account that multiple regimens might be necessary to achieve remission. Despite the main role of multi-agent chemotherapy regimens in EMA-CO resistant GTN, surgery has an important role in curative treatment. Surgical interventions in highly selected and appropriate candidates can improve overall outcome, however it should be considered in early course of management rather than later. Unfortunately, surgery might involve hysterectomy, for these young women, and/or thoracotomy.

Based on the current data and studies, evidence is still limited to suggest which regimen is more superior. Almost all studies are single institution experience, retrospective analyses, and with a relatively a small sample size. Due to the extreme rarity of EMA-CO resistant GTN, it will be challenging to have data based on multicentre prospective randomised clinical trials. Therefore, the management should be individualized based on patient characteristics and previous treatments, and all patients should be treated in experienced institutions where options for appropriate interventions are accessible. Interestingly, the regimen of choice is varied across the world. While EMA-EP is considered the first option in North America and Europe, 5-FU based multi-agent chemotherapy is the the preferred regimen in Asia. Heavily treated patients might get benefit from the introduction of completely different chemotherapeutic agents. In the presence of current positive outcome, high-dose chemotherapy and peripheral blood stem cell support is an option to treat challenging refractory GTN.

Radiotherapy may play a significant role in salvage therapy, mainly in managing brain metastases. In brain metastases, radiotherapy, in combination with chemotherapy, is considered to be tumoricidal and hemostatic. However, radiotherapy should not be given in acutely decompensating patients, due to risk worsening edema, bleeding and death.

\section{Future direction}

It is agreeable that the main management of EMA-CO resistance GTIN is multi-agent chemotherapy regimen. Nevertheless, there is no strong evidence to indicate which regimen showed superior outcome. Dramatic change on the currant approach is not anticipated in near future, especially that the majority of this disease is curable with the available options. However, development of targeted therapy in oncology management, especially in gynecologic oncology, might prove efficacy. Initial report from UK showed promising result with use of Pembrolizumab, as single agent, in high risk and refractory GTN [50]. Pembrolizumab is monoclonal antibodies targeting PD-1 (Programmed Death protein 1) inhibitory signaling which is one of multiple suppressive mechanisms to regulate anticancer T-cell activity. Programmed cell death ligand 1 (PD-L1) is overexpressed by GTN, proposing the ligand is involved in tumor-immune evasion. Pembrolizumab is given as intravenous infusion, well tolerated, and has an acceptable toxicity profile. More data is required to consider Pembrolizumab as an option for such a disease, but that could be soon. An ongoing DART trial (Dual Anti-CTLA-4 and Anti-PD-1 Blockade in Rare tumor), a phase 2 clinical trial evaluates the response rate associated with Nivolumab and Ipilimumab in treating patients with rare tumors, including trophoblastic tumor, could provide more data about the value of monoclonal antibodies in the management of resistant or refractory GTN.

\section{Conflict of interest}

All authors declare that they have no conflict of interest.

\section{References}

1. Lurain JR (2010) Gestational trophoblastic disease I: Epidemiology, pathology, clinical presentation and diagnosis of gestational trophoblastic disease, and management of hydatidiform mole. Am J Obstet Gynecol 203: 531-539. [Crossref]

2. Rodriguez N, Goldstein DP, Berkowitz RS (2010) Treating gestational trophoblastic disease. Expert Opin Pharmacother 11: 3027-3039.

3. Lurain JR, Casanova LA, Miller DS, Rademaker AW (1991) Prognostic factors in gestational trophoblastic tumors: A proposed new scoring system based on multivariate analysis. Am J Obstet Gynecol 164: 611-616. [Crossref]

4. Bower M, Newlands ES, Holden L, Short D, Brock C, et al. (1997) EMA/CO for high-risk gestational trophoblastic tumors: results from a cohort of 272 patients. J Clin Oncol 15: 2636-2643. [Crossref] 
5. Lurain JR, Schink JC (2012) Importance of salvage therapy in the management of highrisk gestational trophoblastic neoplasia. J Reprod Med 57: 219-24. [Crossref]

6. Bolis G, Bonazzi C, Landoni F, Mangili G, Vergadoro F, et al. (1988) EMA/CO Regimen in high-risk gestational trophoblastic tumor (GTT) at the obstetrics and gynaecology departments I and III of Milan university. Gynecol Oncol 31: 439-444. [Crossref]

7. Kim SJ, Bae SN, Kim JH, Kim CT, Han KT, et al (1998) Effects of multiagent chemotherapy and independent risk factors in the treatment of high-risk GTT--25 years experiences of KRI-TRD. Int J Gynaecol Obstet 60 Suppl 1: S85-96. [Crossref]

8. Newlands ES (2003) The management of recurrent and drug-resistant gestational trophoblastic neoplasia (GTN). Bailliere's Best Pract Res Clin Obstet Gynaecol 17: 905-923. [Crossref]

9. Lurain J (2002) Treatment of gestational trophoblastic tumors. Curr Treat Options Oncol 3: 113-124.

10. Ngan HYS, Tam KF, Lam KW, Chan KKL (2006) Relapsed gestational trophoblastic neoplasia: A 20-year experience. J Reprod Med 51: 829-834. [Crossref]

11. Feng F, Xiang Y, Li L, Wan X, Yang X (2009) Clinical parameters predicting therapeutic response to surgical management in patients with chemotherapy-resistant gestational trophoblastic neoplasia. Gynecol Oncol 113: 312-315. [Crossref]

12. Lybol C, Westerdijk K, Sweep F, Ottevanger P, Massuger L, et al. (2012) Human chorionic gonadotropin (hCG) regression nomograms for patients with high-risk gestational trophoblastic neoplasia treated with EMA/CO (etoposide, methotrexate, actinomycin D, cyclophosphamide and vincristine) chemotherapy. Ann Oncol 23: 2903-2906. [Crossref]

13. Rattanaburi A, Boonyapipat S, Supasinth Y (2015) Human chorionic gonadotropin (hCG) regression curve for predicting response to EMA/CO (etoposide, methotrexate, actinomycin D, cyclophosphamide and vincristine) regimen in gestational trophoblastic neoplasia. Asian Pacific J Cancer Prev 16: 5037-5041. [Crossref]

14. Kim SJ, Bae SN, Kim JH, Kim CJ, Jung JK (1998) Risk factors for the prediction of treatment failure in gestational trophoblastic tumors treated with EMA/CO regimen. Gynecol Oncol 71: 247-253. [Crossref]

15. Lurain JR, Nejad B (2005) Secondary chemotherapy for high-risk gestational trophoblastic neoplasia. Gynecol Oncol 97: 618-623. [Crossref]

16. Theodore C, Azab M, Droz JP, Assouline A, George M, et al. (1989) Treatment of high-risk gestational trophoblastic disease with chemotherapy combinations containing cisplatin and etoposide. Cancer 64: 1824-1828. [Crossref]

17. Wang J, Short D, Sebire NJ, Lindsay I, Newlands ES, et al. (2008) Salvage chemotherapy of relapsed or high-risk gestational trophoblastic neoplasia (GTN) with paclitaxel/cisplatin alternating with paclitaxel/ etoposide (TP/TE). Ann Oncol 19: 1578-1583. [Crossref]

18. Feng F, Xiang Y, Wan X, Geng S, Wang T (2011) Salvage combination chemotherapy with floxuridine, dactinomycin, etoposide, and vincristine (FAEV) for patients with relapsed/chemoresistant gestational trophoblastic neoplasia. Ann Oncol 22: 1588-1594. [Crossref]

19. Feng F, Xiang Y (2010) Surgical management of chemotherapy-resistant gestational trophoblastic neoplasia. Expert Rev Anticancer Ther 10: 71-80. [Crossref]

20. Hammond CB, Weed Jr. JC, Currie JL (1980) The role of operation in the current therapy of gestational trophoblastic disease. Am J Obstet Gynecol 136: 844-856. [Crossref]

21. Lurain JR, Singh DK, Schink JC (2006) Role of surgery in the management of high-risk gestational trophoblastic neoplasia. J Reprod Med 51: 773-776. [Crossref]

22. Fleming EL, Garrett L, Growdon WB, Callahan M, Nevadunsky N, et al. (2008) The changing role of thoracotomy in gestational trophoblastic neoplasia at the New England Trophoblastic Disease Center. J Reprod Med 53: 493-498. [Crossref]

23. Clark RM, Nevadunsky NS, Ghosh S, Goldstein DP, Berkowitz RS (2010) The evolving role of hysterectomy in gestational trophoblastic neoplasia at the New England Trophoblastic Disease Center. J Reprod Med 55: 194-198. [Crossref]

24. Tomoda Y, Arii Y, Kaseki S, Asai Y, Gotoh S, et al. (1980) Surgical indications for resection in pulmonary metastasis of choriocarcinoma. Cancer 46: 2723-2730. [Crossref]

25. Kanis MJ, Lurain JR (2016) Pulmonary resection in the management of high-risk gestational trophoblastic neoplasia. Int J Gynecol Cancer 26: 796-800. [Crossref]

26. Cao Y, Xiang Y, Feng F, Wan X, Yang X (2009) Surgical resection in the management of pulmonary metastatic disease of gestational trophoblastic neoplasia. Int $J$ Gynecol Cancer 19: 798-801. [Crossref]
27. El-helw LM, Hancock BW (2007) Treatment of metastatic gestational trophoblastic neoplasia. Lancet Oncol 8: 715-724. [Crossref]

28. Newlands ES, Holden L, Seckl MJ, McNeish I, Strickland S, et al. (2002) Management of brain metastases in patients with high-risk gestational trophoblastic tumors. J Reprod Med 47: 465-471. [Crossref]

29. Newlands ES, Bower M, Holden L, Short D, Seckl MJ, et al. (1998) Management of resistant gestational trophoblastic tumors. J Reprod Med 43: 111-118. [Crossref]

30. Berkowitz RS, Goldstein DP (2009) Current management of gestational trophoblastic diseases. Gynecol Oncol 112: 654-662. [Crossref]

31. Newlands ES, Mulholland PJ, Holden L, Seckl MJ, Rustin GJ (2000) Etoposide and cisplatin/etoposide, methotrexate, and actinomycin D (EMA) chemotherapy for patients with high-risk gestational trophoblastic tumors refractory to EMA/cyclophosphamide and vincristine chemotherapy and patients presenting with metastatic placental site trophoblastic tumors. J Clin Oncol 18: 854-859. [Crossref]

32. Mao Y, Wan X, Lv W, Xie X (2007) Relapsed or refractory gestational trophoblastic neoplasia treated with the etoposide and cisplatin/etoposide, methotrexate, and actinomycin D (EP-EMA) regimen. Int J Gynecol Obstet 98: 44-47. [Crossref]

33. Lu WG, Ye F, Shen YM, Fu YF, Chen HZ, et al. (2008) EMA-CO chemotherapy for high-risk gestational trophoblastic neoplasia: A clinical analysis of 54 patients. Int $J$ Gynecol Cancer 18: 357-362. [Crossref]

34. Osborne R, Covens A, Mirchandani D, Gerulath A (2004) Successful salvage of relapsed high-risk gestational trophoblastic neoplasia patients using a novel paclitaxelcontaining doublet. J Reprod Med 49: 655-661. [Crossref]

35. Song SQ, Wang C, Zhang GN, Shi Y, Zhu Y, et al. (2015) BEP for high-risk gestational trophoblastic tumor: results from a cohort of 45 patients. Eur J Gynaecol Oncol 36 : 726-729. [Crossref]

36. Zhao Y, Zhang W, Duan W (2009) Management of gestational trophoblastic neoplasia with 5-fluorouracil and actinomycin D in northern China. J Reprod Med 5: 88-94. [Crossref]

37. Matsui H, Suzuka K, Iitsuka Y, Yamazawa K, Tanaka N, et al. (2002) Salvage combination chemotherapy with 5 -fluorouracil and actinomycin D for patients with refractory, high-risk gestational trophoblastic tumors. Cancer 95: 1051-1054. [Crossref]

38. Yang J, Xiang Y, Wan X, Feng F, Ren T (2016) Primary treatment of stage IV gestationa trophoblastic neoplasia with floxuridine, dactinomycin, etoposide and vincristine (FAEV): A report based on our 10-year clinical experiences. Gynecol Oncol 143: 6872. [Crossref]

39. Even C, Pautier P, Duvillard P, Floquet A, Kerbrat P, et al. (2014) Actinomycin D, cisplatin, and etoposide regimen is associated with almost universal cure in patients with high-risk gestational trophoblastic neoplasia. Eur J Cancer 50: 2082-2089. [Crossref]

40. Azab M, Droz JP, Theodore C, Wolff JP, Amiel JL (1989) Cisplatin, vinblastine, and bleomycin combination in the treatment of resistant high-risk gestational trophoblastic tumors. Cancer 64: 1829-1832. [Crossref]

41. Wang S, An R, Han X, Zhu K, Xue Y (2006) Combination chemotherapy with 5-fluorouracil, methotrexate and etoposide for patients with high-risk gestational trophoblastic tumors: a report based on our 11-year clinical experiences. Gynecol Oncol 103: 1105-1108. [Crossref]

42. Rathod PS, Kundargi R, Pallavi VR, Vijay CR, Devi UK, et al. (2015) Refractory gestational trophoblastic neoplasia: A novel drug combination with paclitaxel and carboplatin produces durable complete remission. Int J Gynecol Cancer 25: 1737-1741. [Crossref]

43. El-Helw LM, Seckl MJ, Haynes R, Evans LS, Lorigan PC, et al. (2005) Highdose chemotherapy and peripheral blood stem cell support in refractory gestational trophoblastic neoplasia. Br J Cancer 93: 620-621. [Crossref]

44. Benigno BB (2013) High-dose chemotherapy with autologous stem cell support as salvage therapy in recurrent gestational trophoblastic disease. Int J Gynecol Cancer 23: 1331-1333. [Crossref]

45. Yamamoto E, Niimi K, Fujikake K, Nishida T, Murata M, et al. (2016) Highdose chemotherapy with autologous peripheral blood stem cell transplantation for choriocarcinoma: A case report and literature review. Mol Clin Oncol 5: 660-664. [Crossref]

46. Yordan EL, Schlaerth J, Gaddis O, Morrow CP (1987) Radiation therapy in the management of gestational choriocarcinoma metastatic to the central nervous system. Obstet Gynecol 69: 627-630. [Crossref] 
47. Evans AC Jr, Soper JT, Clarke-Pearson DL, Berchuck A, Rodriguez GC, et al. (1995) Gestational trophoblastic disease metastatic to the central nervous system. Gynecol Oncol 59: 226-230. [Crossref]

48. Neubauer NL, Latif N, Kalakota K, Marymont M, Small W, et al. (2012) Brain metastasis in gestational trophoblastic neoplasia: An update. J Reprod Med 57: 288292. [Crossref]
49. Mutch DG, Soper JT, Babcock CJ, Clarke-Pearson DL, Hammond CB (1990) Recurrent gestational trophoblastic disease. Experience of the Southeastern Regional Trophoblastic Disease Center. Cancer 66: 978-982. [Crossref]

50. Ghorani E, Kaur B, Fisher RA, Short D, Joneborg U, et al. (2017) Pembrolizumab is effective for drug-resistant gestational trophoblastic neoplasia. Lancet 390: 2343-2345. [Crossref]

Copyright: (C2019 Babaier A. This is an open-access article distributed under the terms of the Creative Commons Attribution License, which permits unrestricted use, distribution, and reproduction in any medium, provided the original author and source are credited. 